\title{
A patient-centered multidisciplinary cardiac rehabilitation program improves glycemic control and functional outcome in coronary artery disease after percutaneous and surgical revascularization
}

\author{
Andrea Denegri ${ }^{1}$, Valentina A. Rossi ${ }^{2}$, Fabrizio Vaghi ${ }^{3}$, Paolo Di Muro ${ }^{3}$, \\ Martino Regazzi ${ }^{3}$, Tiziano Moccetti ${ }^{3}$, Elena Pasotti ${ }^{3}$, Battista G. Pedrazzini ${ }^{3}$, \\ Mauro Capoferri ${ }^{3}$, Marco Moccetti ${ }^{3}$ \\ ${ }^{1}$ Cardiology Division, Department of Biomedical, Metabolic and Neural Sciences, \\ University of Modena and Reggio Emilia, Policlinico di Modena, Modena, Italy \\ ${ }^{2}$ University Heart Center, University Hospital, Zurich, Switzerland \\ ${ }^{3}$ Cardiocentro Lugano, University of Zurich, Lugano, Switzerland
}

\begin{abstract}
Background: Cardiac rehabilitation (CR) is strongly associated with all-cause mortality reduction in patients with coronary artery disease (CAD). The impact of CR on pathological risk factors, such as impaired glucose tolerance (IGT) and functional recovery remains under debate. The aim of the present study is to determine whether CR had a positive effect beside physical exercise improvement on pathological risk factors in IGT and diabetic patients with CAD.

Methods: One hundred and seventy-one consecutive patients participating in a 3-month CR from January 2014 to June 2015 were enrolled. The primary endpoint was defined as an improvement of peak workload and VO2-peak; glycated hemoglobin (HbA1c) reduction was considered as secondary endpoint.

Results: Euglycemic patients presented a significant improvement in peak workload compared to diabetic patients (from $5.75 \pm 1.45$ to $6.65 \pm 1.84$ METs vs. $4.8 \pm 0.8$ to $4.9 \pm 1.4$ METs , $p=0.018$ ). VO2-peak improved in euglycemic patients (VO2-peak from $19.3 \pm 5.3$ to $22.5 \pm 5.9 \mathrm{~mL}$ ) $/ \mathrm{min} / \mathrm{kg}, p=0.003$ ), while diabetic patients presented only a statistically significant trend (VO2-peak from $16.9 \pm 4.4$ to $18.0 \pm 3.8 \mathrm{~mL} / \mathrm{min} / \mathrm{kg}, p<0.056$ ). Diabetic patients have benefited more in terms of blood glucose control compared to IGT patients (HbA1c from $7.7 \pm 1.0$ to $7.4 \pm 1.1$ compared to $5.6 \pm 0.4$ to $5.9 \pm 0.5, p=0.02$, respectively).

Conclusions: A multidisciplinary CR program improves physical functional capacity in CAD setting, particularly in euglycemic patients. IGT patients as well as diabetic patients may benefit from a CR program, but long-term outcome needs to be clarified in larger studies. (Cardiol J 2022; 29, 1: 72-79)
\end{abstract}

Key words: cardiac rehabilitation, coronary artery disease, diabetes mellitus, reduced glucose tolerance, cardiopulmonary test

Address for correspondence: Andrea Denegri, MD, PhD, Cardiology Division, Department of Biomedical, Metabolic and Neural Sciences, University of Modena and Reggio Emilia, Policlinico di Modena, Modena, Italy, tel: +39 3286574387 , e-mail: denegri.andrea@aou.mo.it; denegriandrea@msn.com

Received: 22.12.2018 Accepted: 19.08.2019 Early publication date: 21.01.2020

This article is available in open access under Creative Common Attribution-Non-Commercial-No Derivatives 4.0 International (CC BY-NC-ND 4.0) license, allowing to download articles and share them with others as long as they credit the authors and the publisher, but without permission to change them in any way or use them commercially. 


\section{Introduction}

Cardiovascular disease and acute coronary syndrome (ACS) represent a major source of morbidity and mortality in Western countries [1]. Cardiac rehabilitation (CR) has been strongly associated with a reduction in all-cause mortality in patients with coronary artery disease (CAD), hospital readmissions, costs and improvement in exercise capacity, quality of life and psychological well-being [2-5]. Therefore, CR is currently a mainstay of post-acute care strategy and is recommended by international guidelines for stable CAD (Class I, Level A). A multi-factorial intervention including patient assessment, physical activity/ /diet/nutritional counselling, exercise training, risk factor control, patient education, psychosocial management, and vocational advice are also recommended for patients with ST-elevation acute myocardial infarction (Class I, Level B), and non ST-elevation myocardial infarction (Class IIa, LevelA) $[6,7]$. Exercise capacity, measured by VO2-peak, is an independent predictor of all-cause and cardiovascular mortality in patients with $\mathrm{CAD}[8,9]$. Diabetic patients are known to be at higher risk for CAD, with a worse prognosis after a myocardial infarction compared to non-diabetic patients $[10,11]$. Previous studies have shown that CR is less effective in these patients, probably due to impaired glycemic control [12]. Less is known about the value of impaired glucose tolerance (IGT) as a predictor of cardiovascular events in the long-term, however this condition seems to be associated with lower functional recovery $[13,14]$. Recently, a positive association between IGT and left ventricular diastolic dysfunction was found in middle-age adults without left ventricular systolic impairment or valvular disease, even after correction for confounding factors [15]. The cardiopulmonary exercise testing (CPET) is commonly performed in patients with CAD to identify post-infarct residual ischemia and to monitor the progress of CR $[16,17]$. The aim of the present study is to determine whether CR had a positive effect on exercise capacity and risk factor control in IGT and diabetic patients with CAD.

\section{Methods}

One hundred and seventy-one consecutive patients referred to Cardiocentro Ticino (Lugano, Switzerland) for CR, from January 2014 to June 2015, were enrolled in the study. Patients with severe renal failure (as defined by RIFLE clas- sification - Risk, Injury, Failure, Loss of kidney function and End-stage renal disease based on creatinine clearance and urinary output) [18], severe peripheral arterial disease, severe respiratory disease or those simply unable to perform exercise training were excluded. Diabetes was diagnosed by plasma fasting glucose $>126 \mathrm{mg} / \mathrm{dL}$ (i.e. $>7.0 \mathrm{mmol} / \mathrm{L}$ ) or by glycated hemoglobin $(\mathrm{HbA} 1 \mathrm{c})>6.5 \%$. A tri-weekly 2 -h session of a comprehensive multidisciplinary $\mathrm{CR}$ program began on hemodynamically stable patients and continued for 3 months. The CR team consisted of physiotherapists, psychologists, nutritionists and an experienced cardiologist in cardiovascular rehabilitation. Each session included one or more group-based therapies, such as education about cardiovascular risk factors, dietary suggestions, and physiotherapy as well as exercise and stress management. Exercise sessions of aerobic exercise lasting $30 \mathrm{~min}$, including a warm-up and a cool-down activity. The intensity of exercise was prescribed individually, based on a target heart rate $<85 \%$ of the theoretical threshold. Demographic information, anthropometric parameters, medical history, ACS type, cardiovascular risk factors, medications as well as laboratory values were collected at baseline and after completing the CR program (at least $>75 \%$ of sessions). A CPET was performed at baseline and at the end of the $\mathrm{CR}$ program and was supervised by an experienced cardiologist. This ergometric CPET was conducted with variable work loads of 10 to 25 Watts every 1 or 2 min (incremental protocol), according to a patient's individual functional autonomy. A measurement of patient cardiopulmonary function, such as maximal metabolic equivalents (METs), peak workload and maximal oxygen consumption (VO2-peak), were collected at baseline and at the end of the CR program.

\section{Statistical analysis}

Variables were expressed as means \pm standard deviation or percentage as appropriate. Comparisons between groups were performed using the two-tailed Student t-test or $\chi^{2}$ test as appropriate. Correlation coefficients were determined by linear regression analysis and statistical significance was determined with the Fisher and Yates test. Multivariable analyses were performed by stepwise linear regression or by stepwise logistic regression as appropriate. A p-value $<0.05$ was considered to be statistically significant. Statistical analysis was performed using the SPSS software (SPSS 22.0 Inc., Chicago IL, USA). 
Table 1. Main characteristics of cardiac rehabilitation (CR) patients according to glycemic status.

\begin{tabular}{|c|c|c|c|}
\hline & $\begin{array}{l}\text { Euglycemic (glycemic } \\
<5.6 \mathrm{mmol} / \mathrm{L}) \\
(\mathrm{n}=88)\end{array}$ & $\begin{array}{l}\text { IGT (glycemic } \\
5.6-7.0 \mathrm{mmol} / \mathrm{L}) \\
(\mathrm{n}=59)\end{array}$ & $\begin{array}{c}\text { Diabetics (glycemic } \\
>7.0 \mathrm{mmol} / \mathrm{L}) \\
(\mathrm{n}=24)\end{array}$ \\
\hline Age & 60,45 & 63,35 & 69,30 \\
\hline Male & 53 & 66 & 24 \\
\hline Familial history of CHD & 25 & 23 & 4 \\
\hline Hypertension & 32 & 42 & 20 \\
\hline Dyslipidemia & 36 & 40 & 11 \\
\hline Diabetes & 1 & 12 & 21 \\
\hline Smoking & 35 & 38 & 6 \\
\hline Statin therapy & 56 & 61 & 21 \\
\hline ACEI & 40 & 41 & 19 \\
\hline Beta-blockers & 59 & 68 & 17 \\
\hline Acetylsalicylic acid & 64 & 68 & 24 \\
\hline Stable angina & 28 & 20 & 9 \\
\hline Unstable angina & 3 & 2 & 0 \\
\hline NSTEMI & 18 & 4 & 4 \\
\hline STEMI & 25 & 22 & 9 \\
\hline PTCA & 55 & 40 & 13 \\
\hline CABG (also previous) & 23 & 12 & 12 \\
\hline Waist $>88$ or $>102 \mathrm{~cm}$ & 31 & 33 & 17 \\
\hline Weight $>60$ or $>70 \mathrm{~kg}$ & 50 & 66 & 23 \\
\hline$\Delta$ Glucose & $-0.16 \pm 0.46(p=0.25)$ & $-0.35 \pm 0.75(p=0.02)$ & $0.52 \pm 1.40(p<0.05)$ \\
\hline$\Delta \mathrm{HbA} 1 \mathrm{c}$ & $0.40 \pm 0.97(p=0.67)$ & $0.28 \pm 0.53(p=0.28)$ & $-0.29 \pm 1.20(p=0.02)$ \\
\hline
\end{tabular}

Data are presented as mean \pm standard deviation or percentage. ACEI - angiotensin converting enzyme inhibitor; CABG - coronary artery by-pass graft; CHD — chronic heart disease; HbA1c - glycated hemoglobin; IGT — impaired glucose tolerance; NSTEMI - non-ST-segment elevation myocardial infarction; PTCA — percutaneous transluminal coronary angioplasty; STEMI — ST-segment elevation myocardial infarction

\section{Results}

Out of 171 patients enrolled in the study, 148 (86.5\%) completed the CR program; 87 (50.9\%) patients presented ACS in the prior 4 weeks and $108(63.1 \%)$ underwent a percutaneous transluminal coronary angioplasty (PTCA). After 1 week, $23(13.4 \%)$ patients dropped out the CR program and another 4 patients were excluded from the analysis because of attendance of less than $75 \%$ of the sessions (less than 28 of the 36 sessions). Out of 144 patients who completed the CR program, $34(23.6 \%)$ patients were already known to have diabetes; 3 (2.1\%) patients were newly diagnosed. Patients with a plasma fasting glucose between 100 and $126 \mathrm{mg} / \mathrm{dL}$ (i.e. $5.56 \mathrm{mmol} / \mathrm{L}$ and $7.0 \mathrm{mmol} / \mathrm{L}$ ), independent of their history, were classified as IGT patients; of these $47(32.6 \%)$ were newly diagnosed. The baseline characteristics of the 171 patients, divided in three groups according to their baseline fasting glucose and enrolled in the study are summarized in Table 1 .

\section{Effects on exercise capacity based on glucose control}

Exercise capacity pre- and post-CR expressed by CPET parameters is summarized in Table 2 . All groups showed significant intra-group improvement (Fig. 1) considering workload peak and VO2-peak (except IGT patients). Euglycemic patients benefited the most in terms of exercise capacity improvement $(5.7 \pm 1.4$ to $6.6 \pm 1.8 \mathrm{MET}$, $\mathrm{p}=0.018)$. IGT patients presented a lower functional capacity recovery when compared to euglycemic patients $(5.9 \pm 1.9$ to $6.3 \pm 1.8 \mathrm{METs}$, $\mathrm{p}=0.413)$ as well as diabetic patients $(4.8 \pm 0.8$ to $4.9 \pm 1.4, \mathrm{p}=0.072$ ).

A significant improvement in VO2-peak after completing $\mathrm{CR}$ was found in euglycemic patients (VO2-peak from $19.3 \pm 5.3$ to $22.5 \pm 5.9 \mathrm{~mL} / \mathrm{min} /$ $/ \mathrm{kg}, \mathrm{p}=0.003$ ) and also in this case, IGT patients showed less benefit compared to euglycemic patients (VO2-peak from $20.2 \pm 6.4$ to $21.5 \pm 7.0$ $\mathrm{mL} / \mathrm{min} / \mathrm{kg}, \mathrm{p}=0.42$ ). Diabetic patients presented only a positive trend in VO2-peak compared to IGT 
Table 2. Cardiopulmonary test values pre- and post-cardiac rehabilitation (CR).

\begin{tabular}{lcccc}
\hline & $\begin{array}{c}\text { Euglycemic }(<5.6) \\
(\mathbf{n}=\mathbf{6 3})\end{array}$ & $\begin{array}{c}\text { IGT (5.6-7.0) } \\
(\mathbf{n = 6 6 )}\end{array}$ & $\begin{array}{c}\text { Diabetics }(>\mathbf{7 . 0}) \\
(\mathbf{n}=\mathbf{1 9})\end{array}$ \\
\hline Watt pre-CR & $128.5 \pm 41.2$ & $128.4 \pm 40.0$ & $104.7 \pm 38.2$ & $\mathbf{P}$ \\
Watt post-CR & $137.4 \pm 44.0$ & $142.1 \pm 46.1$ & $116.1 \pm 41.3$ & 0.08 \\
METs pre-CR & $5.7 \pm 1.4$ & $5.9 \pm 1.9$ & $4.8 \pm 0.8$ & $\mathbf{0 . 0 3}$ \\
METs post-CR & $6.6 \pm 1.8$ & $6.3 \pm 1.8$ & $4.9 \pm 1.4$ & $\mathbf{0 . 0 1}$ \\
VO2-peak pre-CR & $19.3 \pm 5.3$ & $20.1 \pm 6.3$ & $16.9 \pm 3.8$ & 0.07 \\
VO2-peak post-CR & $22.5 \pm 5.9$ & $21.5 \pm 7.0$ & $18.0 \pm 4.4$ & $<\mathbf{0 . 0 5}$ \\
VO2 threshold pre-CR & $13.9 \pm 4.2$ & $14.7 \pm 4.3$ & $12.3 \pm 2.5$ & 0.11 \\
VO2 threshold post-CR & $16.0 \pm 4.6$ & $16.3 \pm 4.6$ & $13.7 \pm 3.9$ & 0.05 \\
O2 beat pre-CR & $12.3 \pm 3.1$ & $13.0 \pm 3.5$ & $11.6 \pm 2.3$ & 0.35 \\
O2 beat post-CR & $13.1 \pm 3.4$ & $13.5 \pm 3.7$ & $11.9 \pm 2.9$ & 0.19 \\
Breath reserve pre-CR & $40.8 \pm 15.9$ & $38.1 \pm 15.3$ & $37.0 \pm 13.5$ & 0.33 \\
Breath reserve post-CR & $37.9 \pm 17.1$ & $37.0 \pm 14.9$ & $33.4 \pm 14.6$ & 0.31 \\
\hline
\end{tabular}

Data are presented as mean \pm standard deviation. Statistical significance is shown for euglycemic patients vs. diabetics. IGT — impaired glucose tolerance; METs - metabolic equivalents; VO2 - oxygen volume

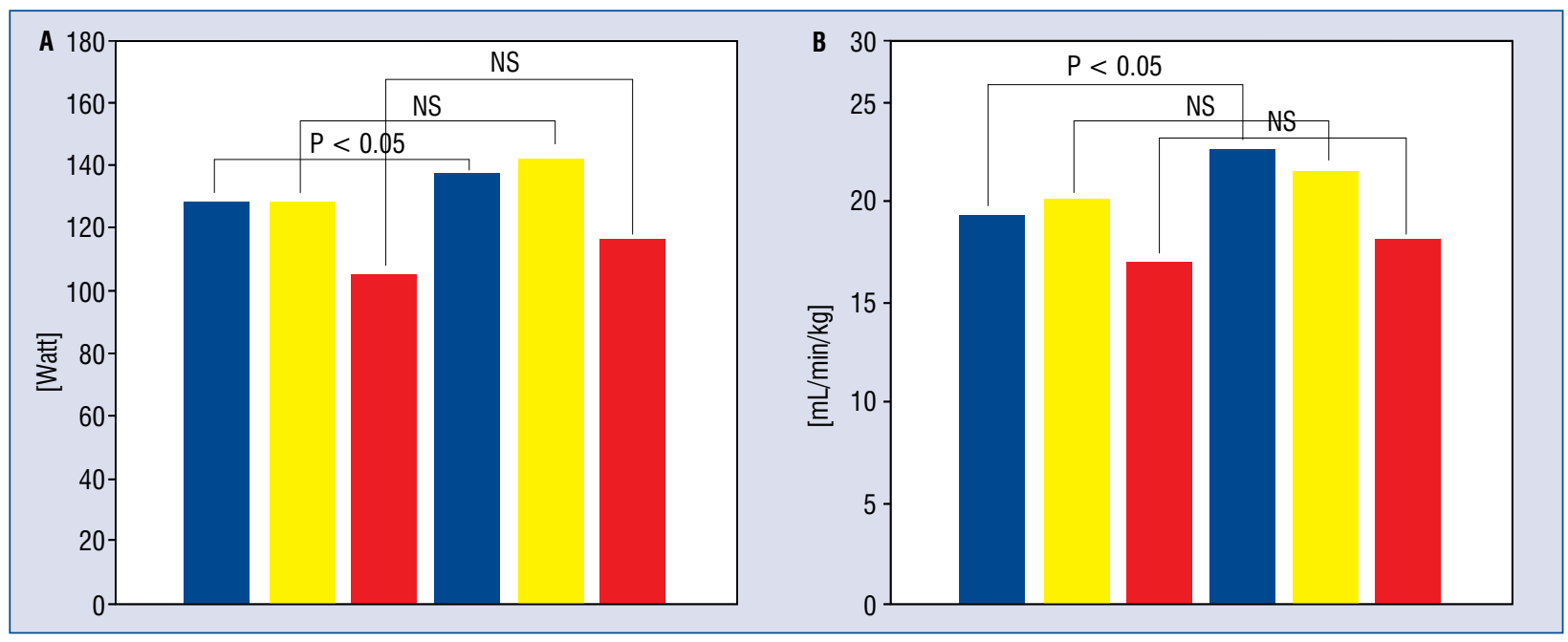

Figure 1. Peak workload and VO2-peak improvement; A. Peak workload comparison between euglycemic (blue bars), impaired glucose tolerance (IGT; yellow bars) and diabetic patients (red bars); B. VO2-peak comparison between euglycemic (blue bars), IGT (yellow bars) and diabetic patients (red bars); NS — not significant.

(VO2-peak $17.0 \pm 3.8 \mathrm{~mL} / \mathrm{min} / \mathrm{kg}$ vs. $18.1 \pm 4.4$ $\mathrm{mL} / \mathrm{min} / \mathrm{kg}, \mathrm{p}=0.056)$. IGT patients presented the most significant benefit in terms of fasting glucose reduction, compared to diabetic patients (plasma fasting glucose $6.5 \pm 0.5 \mathrm{mmol} / \mathrm{L}$ to $6.2 \pm$ $\pm 0.9 \mathrm{mmol} / \mathrm{L}$ vs. $8.1 \pm 1.8 \mathrm{mmol} / \mathrm{L}$ to $8.2 \pm$ $\pm 1.9 \mathrm{mmol} / \mathrm{L}, \mathrm{p}=0.002$ ). Diabetic patients, on the other hand, showed a more significant reduction of HbA1c levels compared to IGT patients (HbA1c $7.7 \pm 1.1 \%$ to $7.5 \pm 1.2 \%$ vs. $5.6 \pm 0.4 \%$ to $6.0 \pm 0.5 \%, \mathrm{p}=0.002)$. Finally, a trend showing an inverse correlation was found between baseline fasting glucose levels and $\Delta \mathrm{VO} 2$-peak $(\Delta \mathrm{VO} 2-$ -peak $=6.419925-0.721243 *$ fasting glucose, $\mathrm{p}=0.11$, Fig. 2).

\section{Discussion}

In this study, results of a comprehensive $\mathrm{CR}$ program for CAD patients from a single center experience are presented (Cardiocentro Ticino, Lugano, Switzerland). In the current population, $13.4 \%$ of patients quit the CR program after 1 week. This dropout rate is in line with the data previously 


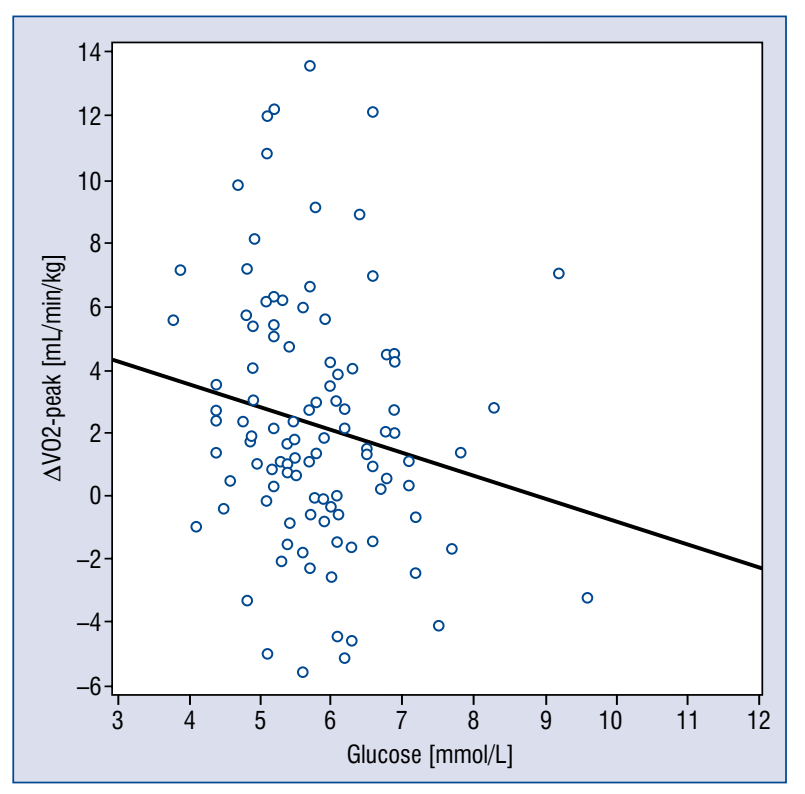

Figure 2. Linear regression, showing an inverse correlation between fasting glucose and VO2-peak improvement, suggesting that response to cardiac rehabilitation may be impaired by poor glycemic control.

reported in the literature [19]. In a big prospective study, including more than 25,000 patients with at least one vessel $\mathrm{CAD}$, diabetic patients were more likely to leave the CR program (odds ratio [OR] $0.65,95 \%$ confidence interval [CI] 0.59-0.72), and, despite being less referred, women experienced a greater relative mortality benefit compared to men [20].

\section{Effects of CR programs on} cardiovascular risk factors

Exercise capacity measured by VO2-peak represents a strong predictor of survival in patients with $\mathrm{CAD}$ and is positively related to improvement in terms of morbidity [21].

High-intensity interval training protocols have been developed and have been shown to lead to a significant increase in functional capacity compared to moderate continuous training [22]. International Guidelines recommend CR programs including a multimodal behavioral intervention for all patients with established CAD [6, 7].

Exercise is associated with improvements of typical cardiovascular risk factor control such as obesity, diabetes mellitus and hypertension [23]. In the present population, a reduction in weight as well as in waist circumference in all patients was found, independently from glycemic status, although these results were not statistically significant as reported in other previous studies published [24]. Moreover, CR is associated with an increase of muscular mass; therefore, weight loss may not reflect by itself a reduction in cardiovascular risk. An increase in oxygen peak consumption or improvement in glycemic control thus represent more useful indicators.

\section{Effects of CR programs based on glycemic status}

The combination of aerobic and resistance training has been shown to be highly effective in reducing cardiovascular risk factors in patients with type 2 diabetes mellitus and is currently recommended by the American College of Sports Medicine and American Heart Association [25, $26]$. In the analyses, it was found that IGT patients presented a more significant reduction in plasma fasting glucose compared to diabetic patients. On the other hand, diabetic patients showed a more significant reduction of $\mathrm{HbA} 1 \mathrm{c}$ levels, compared to IGT patients. Based on these results, it can be extrapolated that these patients could benefit, in terms of glycemic control, from a longer CR program.

The role of $\mathrm{CR}$ as long-term therapy to reduce cardiovascular risk factors after ACS is well established. In a prospective study including 846 patients treated with aorto-coronary by-pass, $\mathrm{CR}$ attendance was associated with a significant reduction of 10-year all-cause mortality and CR program completion was the most important indicator for survival [27]. However, no differences in mortality according to glycemic status were found.

In in vitro studies, hyperglycemia has been shown to lead to oxidative stress and thus, indirectly, to increase myocyte apoptosis, both in chronic and in acute settings [28, 29]. In the DARE study, a prospective multicenter study, 64 patients with diabetes mellitus type 2 were enrolled in a CR program after ACS. Patients were randomized according to baseline diabetes therapy; patients with better glycemic control, as measured by fructosamine levels, a parameter of short-term glycemic control, showed higher values of VO2-peak at the end of CR [19]. In another prospective study including 682 patients undergoing CR after ACS, diabetic subjects presented a lower functional capacity at baseline compared to non-diabetics. Nevertheless, diabetics patients presented a significant improvement, expressed in METs and exercise duration, similar to those achieved by non-diabetic patients [30]. These findings were confirmed in another 
study including heart failure patients [31]. In the current study, it was also found that patients with diabetes have a lower functional capacity at baseline, with an improvement in functional capacity, expressed in terms of both higher peak workload (METs) and VO2-peak values at the end of the $\mathrm{CR}$ program when compared to IGT patients. Euglycemic patients, on the contrary, significantly improved both these parameters compared to diabetic patients.

Data from the Italian SurveY on carDiac rEhabilitation (ISYDE-2008) including 2281 patients referred to $\mathrm{CR}$ showed that patients with diabetes had more comorbidities and $23 \%$ of them were not able to perform any physical performance testing at all. The authors concluded that this finding might have prognostic relevance. A bias in the study involving diabetic patients undergoing $\mathrm{CR}$ has thus to be considered, as these patients may have been directly excluded from enrollment in CR programs [32].

In the present study, euglycemic patients benefited the most from the CR program. IGT patients, however, presented a significant improvement of glycemic control compared to diabetic patients in terms of plasma fasting glucose. Diabetic patients, on the other hand, showed a statistically significant reduction of $\mathrm{HbA1c}$. Taken together, these data suggest that improvement in glycemic control during CR may contribute to optimize functional recovery expressed in terms of workload- and VO2-peak, independently from other factors. These improvements are probably due to $\mathrm{CR}$ itself, and were independent of underlying therapy for diabetes. Several studies, however, failed to demonstrate the effectiveness of CR in diabetic patients [33, 34], although, according to some other authors, CR should be effective for these patients as well [35]. However, the discrepancies in these studies may be related to the heterogeneity of patients considered. In the current study, it was found that fasting glucose at baseline inversely correlated with VO2-peak improvement and this finding is in line with previously published data $[12,36]$. Poor glycemic control seems to have unfavorable effects on cardiomyocytes and muscular cells, promoting overproduction of reactive oxygen species, alterations of myocardial endo-plasmatic reticulum, dysfunction of calcium metabolism and impairment of mitochondria metabolism [29, 37-39]. On the other hand, good glycemic control during CR may improve the VO2-peak [17] and may play a key role for a better long-term prognosis as well.

\section{Limitations of the study}

The retrospective analysis, as well as the lack of a control group, represent a limitation of this study, that is also burdened by a small number of patients, all Caucasian. Larger prospective studies are needed to better clarify the role of CR in diabetic patients.

\section{Conclusions}

This single-center experience showed how a multidisciplinary $\mathrm{CR}$ program provides better outcomes in terms of exercise capacity for euglycemic patients compared to IGT and diabetics patients. These latter patients could benefit from a longer CR program, overall in terms of glycemic control, independently from hypoglycemic therapies. The efficacy of CR in diabetic patients needs to be clarified in larger and prospective studies.

\section{Acknowledgements}

The authors appreciate the work of the whole rehabilitation team and cardiovascular research service of Cardiocentro Ticino, Lugano, Switzerland.

\section{Conflict of interest: None declared}

\section{References}

1. Lüscher TF. Outcomes of acute coronary syndromes: clinical presentation, gender, inflammation, and cell therapy. Eur Heart J. 2017; 38(3): 125-129, doi: 10.1093/eurheartj/ehw676, indexed in Pubmed: 28158616.

2. Anderson L, Thompson DR, Oldridge N, et al. Exercise-based cardiac rehabilitation for coronary heart disease. Cochrane Database Syst Rev. 2016; 67(1): CD001800-12, doi: 10.1002/14651858. CD001800.pub3, indexed in Pubmed: 26730878.

3. Rauch B, Davos CH, Doherty P, et al. The prognostic effect of cardiac rehabilitation in the era of acute revascularisation and statin therapy: A systematic review and meta-analysis of randomized and non-randomized studies - The Cardiac Rehabilitation Outcome Study (CROS). Eur J Prev Cardiol. 2016; 23(18): 1914-1939, doi: 10.1177/2047487316671181, indexed in Pubmed: 27777324.

4. Whalley B, Rees K, Davies P, et al. Psychological interventions for coronary heart disease. Cochrane Database Syst Rev. 2011(8): CD002902, doi: 10.1002/14651858.CD002902.pub3, indexed in Pubmed: 21833943.

5. Wong WP, Feng J, Pwee KHo, et al. A systematic review of economic evaluations of cardiac rehabilitation. BMC Health Serv Res. 2012; 12: 243, doi: 10.1186/1472-6963-12-243, indexed in Pubmed: 22873828 .

6. Piepoli MF, Hoes AW, Agewall S, et al. 2016 European Guidelines on cardiovascular disease prevention in clinical practice: The Sixth Joint Task Force of the European Society of Cardiology and Other Societies on Cardiovascular Disease Prevention in 
Clinical Practice (constituted by representatives of 10 societies and by invited experts)Developed with the special contribution of the European Association for Cardiovascular Prevention \& Rehabilitation (EACPR). Eur Heart J. 2016; 37(29): 2315-2381, doi: 10.1093/eurheartj/ehw106, indexed in Pubmed: 27222591.

7. Piepoli MF, Corrà U, Adamopoulos $\mathrm{S}$, et al. Secondary prevention in the clinical management of patients with cardiovascular diseases. Core components, standards and outcome measures for referral and delivery: a policy statement from the cardiac rehabilitation section of the European Association for Cardiovascular Prevention \& Rehabilitation. Endorsed by the Committee for Practice Guidelines of the European Society of Cardiology. Eur J Prev Cardiol. 2014; 21(6): 664-681, doi: 10.1177/2047487312449597, indexed in Pubmed: 22718797.

8. Brawner CA, Al-Mallah MH, Ehrman JK, et al. Change in Maximal Exercise Capacity Is Associated With Survival in Men and Women. Mayo Clin Proc. 2017; 92(3): 383-390, doi: 10.1016/j. mayocp.2016.12.016, indexed in Pubmed: 28185659.

9. Vanhees L, Fagard R, Thijs L, et al. Prognostic value of training-induced change in peak exercise capacity in patients with myocardial infarcts and patients with coronary bypass surgery. Am J Cardiol. 1995; 76(14): 1014-1019, doi: 10.1016/s00029149(99)80287-2, indexed in Pubmed: 7484853.

10. Rao Kondapally Seshasai S, Kaptoge S, Thompson A, et al. Emerging Risk Factors Collaboration. Diabetes mellitus, fasting glucose, and risk of cause-specific death. N Engl J Med. 2011; 364(9): 829-841, doi: 10.1056/NEJMoa1008862, indexed in Pubmed: 21366474.

11. Krempf M, Parhofer KG, Steg PhG, et al. Cardiovascular event rates in diabetic and nondiabetic individuals with and without established atherothrombosis (from the REduction of Atherothrombosis for Continued Health [REACH] Registry). Am J Cardiol. 2010; 105(5): 667-671, doi: 10.1016/j.amjcard.2009.10.048, indexed in Pubmed: 20185014.

12. Vergès $B$, Patois-Vergès $B$, Cohen $M$, et al. Effects of cardiac rehabilitation on exercise capacity in Type 2 diabetic patients with coronary artery disease. Diabet Med. 2004; 21(8): 889-895, doi: 10.1111/j.1464-5491.2004.01262.x, indexed in Pubmed: 15270793.

13. Khosravi A, Gharipour M, Nezafati P, et al. Pre-hypertension, pre-diabetes or both: which is best at predicting cardiovascular events in the long term? J Hum Hypertens. 2017; 31(6): 382 -387, doi: 10.1038/jhh.2016.42, indexed in Pubmed: 27334522.

14. Russo N, Compostella L, Fadini G, et al. Prediabetes influences cardiac rehabilitation in coronary artery disease patients. Eur J Prev Cardiol. 2012; 19(3): 382-388, doi: 10.1177/1741826711404503, indexed in Pubmed: 21450564.

15. Milwidsky A, Maor E, Kivity S, et al. Impaired fasting glucose and left ventricular diastolic dysfunction in middle-age adults: a retrospective cross-sectional analysis of 2971 subjects. Cardiovasc Diabetol. 2015; 14: 119, doi: 10.1186/s12933-015-0282-4, indexed in Pubmed: 26369690.

16. Smolis-Bąk E, Rymuza H, Kazimierska B, et al. Improvement of exercise tolerance in cardiopulmonary testing with sustained safety after regular training in outpatients with systolic heart failure (NYHA III) and an implantable cardioverter-defibrillator. Prospective 18-month randomized study. Arch Med Sci. 2017; 13(5): 1094-1101, doi: 10.5114/aoms.2016.61938, indexed in Pubmed: 28883851.

17. Lim SK, Han JY, Choe YR. Comparison of the Effects of Cardiac Rehabilitation Between Obese and Non-obese Patients After Acute
Myocardial Infarction. Ann Rehabil Med. 2016; 40(5): 924-932, doi: 10.5535/arm.2016.40.5.924, indexed in Pubmed: 27847723.

18. Ricci $Z$, Cruz D, Ronco C. The RIFLE criteria and mortality in acute kidney injury: A systematic review. Kidney Int. 2008; 73(5): 538-546, doi: 10.1038/sj.ki.5002743, indexed in Pubmed: 18160961.

19. Vergès $\mathrm{B}$, Patois-Vergès $\mathrm{B}$, Iliou $\mathrm{MC}$, et al. DARE Study group. Influence of glycemic control on gain in VO2 peak, in patients with type 2 diabetes enrolled in cardiac rehabilitation after an acute coronary syndrome. The prospective DARE study. BMC Cardiovasc Disord. 2015; 15: 64, doi: 10.1186/s12872-015-0055-8, indexed in Pubmed: 26152221.

20. Colbert JD, Martin BJ, Haykowsky MJ, et al. Cardiac rehabilitation referral, attendance and mortality in women. Eur J Prev Cardiol. 2015; 22(8): 979-986, doi: 10.1177/2047487314545279, indexed in Pubmed: 25278001.

21. Nilsson BB, Lunde P, Grøgaard HK, et al. Long-Term Results of High-Intensity Exercise-Based Cardiac Rehabilitation in Revascularized Patients for Symptomatic Coronary Artery Disease. Am J Cardiol. 2018; 121(1): 21-26, doi: 10.1016/j.amjcard.2017.09.011, indexed in Pubmed: 29096886.

22. Jaureguizar KV, Vicente-Campos D, Bautista LR, et al. Effect of High-Intensity Interval Versus Continuous Exercise Training on Functional Capacity and Quality of Life in Patients With Coronary Artery Disease: A RANDOMIZED CLINICAL TRIAL. J Cardiopulm Rehabil Prev. 2016; 36(2): 96-105, doi: 10.1097/ HCR.0000000000000156, indexed in Pubmed: 26872000.

23. Gregg E, Jakicic J, Blackburn G, et al. Association of the magnitude of weight loss and changes in physical fitness with longterm cardiovascular disease outcomes in overweight or obese people with type 2 diabetes: a post-hoc analysis of the Look AHEAD randomised clinical trial. Lancet Diabetes Endocrinol. 2016; 4(11): 913-921, doi: 10.1016/S2213-8587(16)30162-0, indexed in Pubmed: 27595918.

24. Gardiner FW, Regan E, Nwose EU, et al. Outpatient cardiac rehabilitation: Effects on patient improvement outcomes. Diabetes Metab Syndr. 2017; 11 Suppl 2: S1025-S1030, doi: 10.1016/j. dsx.2017.07.034, indexed in Pubmed: 28781162.

25. Albright A, Franz M, Hornsby G, et al. American College of Sports Medicine position stand. Exercise and type 2 diabetes. Med Sci Sports Exerc. 2000; 32(7): 1345-1360, doi: 10.1097/00005768200007000-00024, indexed in Pubmed: 10912903.

26. Marwick TH, Hordern MD, Miller T, et al. Exercise training for type 2 diabetes mellitus: impact on cardiovascular risk: a scientific statement from the American Heart Association. Circulation. 2009; 119(25): 3244-3262, doi: 10.1161/CIRCULATIONAHA.109.192521, indexed in Pubmed: 19506108.

27. Pack QR, Goel K, Lahr BD, et al. Participation in cardiac rehabilitation and survival after coronary artery bypass graft surgery: a community-based study. Circulation. 2013; 128(6): 590-597, doi: 10.1161/CIRCULATIONAHA.112.001365, indexed in Pubmed: 23836837.

28. Younce CW, Wang K, Kolattukudy PE. Hyperglycaemia-induced cardiomyocyte death is mediated via MCP-1 production and induction of a novel zinc-finger protein MCPIP. Cardiovasc Res. 2010; 87(4): 665-674, doi: 10.1093/cvr/cvq102, indexed in Pubmed: 20356868.

29. Su H, Ji L, Xing W, et al. Acute hyperglycaemia enhances oxidative stress and aggravates myocardial ischaemia/reperfusion injury: role of thioredoxin-interacting protein. J Cell Mol Med. 2013; 17(1): 181-191, doi: 10.1111/j.1582-4934.2012.01661.x, indexed in Pubmed: 23305039. 
30. Toste S, Viamonte S, Barreira A, et al. Cardiac rehabilitation in patients with type 2 diabetes mellitus and coronary disease: a comparative study. Rev Port Cardiol. 2014; 33(10): 599-608, doi: 10.1016/j.repc.2014.01.026, indexed in Pubmed: 25307705.

31. Sabbag A, Mazin I, Rott D, et al. The prognostic significance of improvement in exercise capacity in heart failure patients who participate in cardiac rehabilitation programme. Eur J Prev Cardiol. 2018; 25(4): 354-361, doi: 10.1177/2047487317750427, indexed in Pubmed: 29313373.

32. Giallauria F, Fattirolli F, Tramarin R, et al. Clinical characteristics and course of patients with diabetes entering cardiac rehabilitation. Diabetes Res Clin Pract. 2015; 107(2): 267-272, doi: 10.1016/j.diabres.2014.11.006, indexed in Pubmed: 25497465.

33. Savage PD, Antkowiak M, Ades PA. Failure to improve cardiopulmonary fitness in cardiac rehabilitation. J Cardiopulm Rehabil Prev. 2009; 29(5): 284-91; quiz 292, doi: 10.1097/ HCR.0b013e3181b4c8bd, indexed in Pubmed: 19935140.

34. Vergès $\mathrm{B}$, Patois-Vergès $\mathrm{B}$, Cohen $\mathrm{M}$, et al. Effects of cardiac rehabilitation on exercise capacity in Type 2 diabetic patients with coronary artery disease. Diabet Med. 2004; 21(8): 889-895, doi: 10.1111/j.1464-5491.2004.01262.x, indexed in Pubmed: 15270793
35. Banzer JA, Maguire TE, Kennedy CM, et al. Results of cardiac rehabilitation in patients with diabetes mellitus. Am J Cardiol. 2004; 93(1): 81-84, doi: 10.1016/j.amjcard.2003.09.017, indexed in Pubmed: 14697472.

36. Fang ZY, Sharman J, Prins JB, et al. Determinants of exercise capacity in patients with type 2 diabetes. Diabetes Care. 2005; 28(7): 1643-1648, doi: 10.2337/diacare.28.7.1643, indexed in Pubmed: 15983314.

37. Lakshmanan AP, Harima M, Suzuki K, et al. The hyperglycemia stimulated myocardial endoplasmic reticulum (ER) stress contributes to diabetic cardiomyopathy in the transgenic nonobese type 2 diabetic rats: a differential role of unfolded protein response (UPR) signaling proteins. Int J Biochem Cell Biol. 2013; 45(2): 438-447, doi: 10.1016/j.biocel.2012.09.017, indexed in Pubmed: 23032698.

38. Pang Yi, Hunton DL, Bounelis P, et al. Hyperglycemia inhibits capacitative calcium entry and hypertrophy in neonatal cardiomyocytes. Diabetes. 2002; 51(12): 3461-3467, doi: 10.2337/diabetes.51.12.3461, indexed in Pubmed: 12453900.

39. Kelley DE, He J, Menshikova EV, et al. Dysfunction of Mitochondria in Human Skeletal Muscle in Type 2 Diabetes. Diabetes. 2002; 51(10): 2944-2950, doi: 10.2337/diabetes.51.10.2944. 